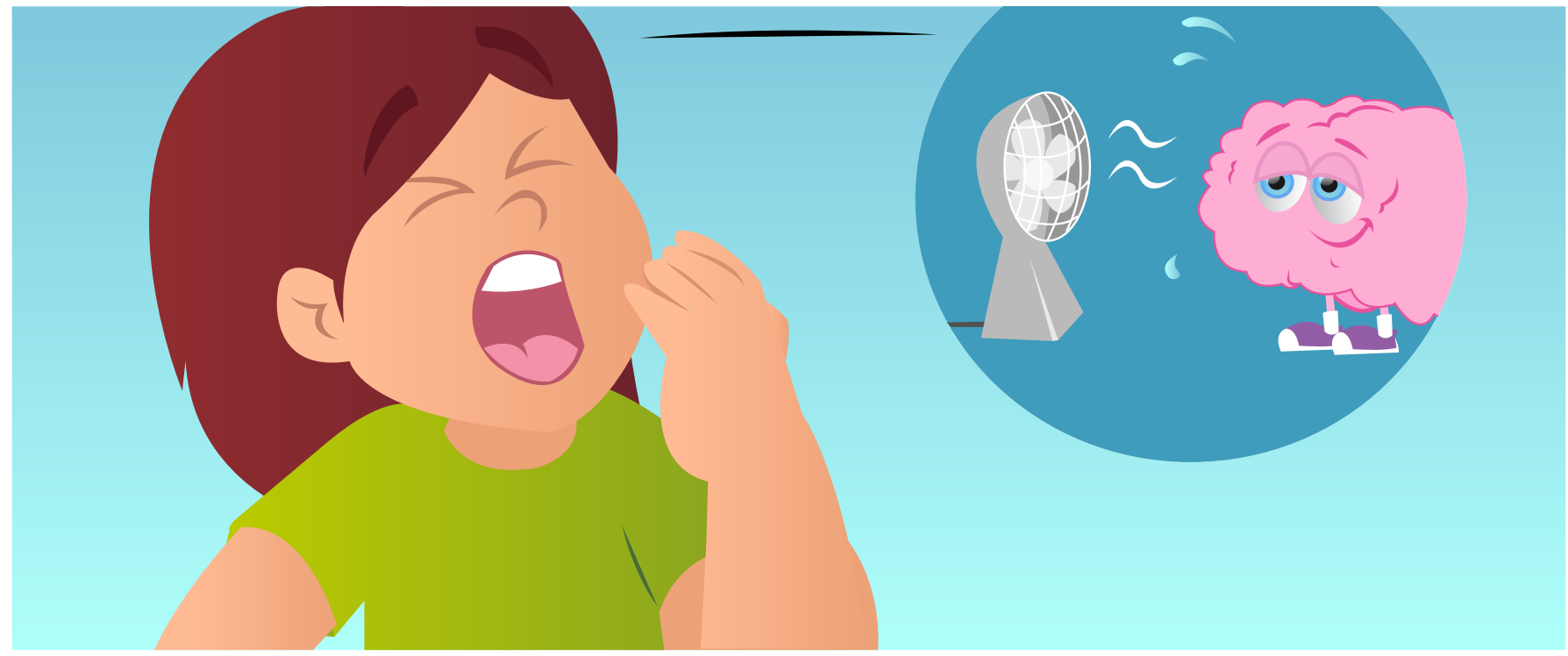

\title{
YAWNS ARE COOL
}

\section{Andrew C. Gallup ${ }^{1 *}$ and Omar Tonsi Eldakar ${ }^{2}$}

${ }^{1}$ Department of Social and Behavioral Sciences, SUNY Polytechnic Institute, Utica, NY, United States, ${ }^{2}$ Department of Biological Sciences, Nova Southeastern University, Fort Lauderdale, FL, United States

\section{REVIEWED BY:}

Although we yawn each and every day, most people have little understanding of why we do it. In fact, the function of yawning has remained mysterious for centuries, even among scientists, and this has only changed quite recently. Contrary to what people have believed for a long time, it is now understood that yawns have nothing to do with breathing or the amount of oxygen we are taking in. Instead, new and growing research has revealed that yawns serve as a brain cooling mechanism. This new perspective on yawning as a response to elevated brain temperature has transformed our understanding of this commonly overlooked and misinterpreted behavior. This information might be useful for treating and diagnosing medical conditions that are accompanied by frequent yawning and for monitoring and improving our brain's performance throughout the day.

\section{EVERYONE YAWNS}

Yawning can be defined as a powerful opening of the jaw with a deep inhalation of air, followed by an effortless closure of the jaw with exhalation of breath. Yawning is something we all do each and every day, and it is a behavior that we commonly observe in other animals as well. Yawns are easy to identify, as they 
look basically the same in most mammals and birds. Humans begin yawning in the womb before they take their first breath and continue to yawn throughout their lives. Yawns are "contagious" - we yawn when we see others yawn, and even when we read about yawning (consider this a warning). However, we also yawn when we are alone, and after all, someone has to yawn first, even if yawning is contagious. This type of yawning, which is done without seeing or reading about other yawns, is referred to as spontaneous yawning.

Spontaneous yawning often occurs at night when we are sleepy, and upon waking in the morning. It is widely recognized that we tend to yawn when we are bored, and thus it is quite common across various cultures around the globe to believe that yawns serve as a signal of sleepiness and disinterest. However, yawning also occurs when people and animals are alert, not just when they are tired or bored, and therefore yawns are more complicated than you might think. Even though there are a lot of popular stories about the purpose of yawns, scientists have only recently discovered yawning's true function.

\section{THE MYSTERY OF YAWNING}

When thinking about why we yawn, people mostly pay attention to the respiratory, or breathing, aspect. When breathing, we inhale to increase our oxygen supply, and we exhale to get rid of excess carbon dioxide. So, the deep breath that accompanies yawning has led many people to believe that the purpose of yawns is to increase oxygen levels. While this explanation seems to make good sense, research conducted 30 years ago firmly rejected this idea. In a clear test of whether yawning was caused by low oxygen levels, Dr. Robert Provine et al. designed an experiment in which they changed the content of the air that was inhaled by participants in the laboratory and then witnessed the effects that the air had on yawning [1]. The researchers had separate conditions where participants either inhaled air with extra oxygen or extra carbon dioxide. These experiments demonstrated that neither breathing pure oxygen nor increased levels of carbon dioxide altered the rate of yawning in humans. In other words, the results of this study revealed that yawning was unaffected by the amount of oxygen in the air, and that yawning and breathing are controlled by separate mechanisms.

More recent research has begun to study how the powerful stretching of the jaw that defines yawning, in combination with the deep inhalation of air, might cause a change in the mental state of the person or animal yawning, such as a shift from feeling sleepy to feeling more awake [2]. A large number of studies using animals have shown that yawns tend to occur when individuals feel anxious about something that is about to happen, or right after periods of stress. These conditions often lead to increases (rather than decreases) in movement and brain activity [3]. Therefore, contrary to the popular belief that yawns are a sign of sleepiness and boredom, it is becoming more widely accepted within the scientific community that yawns somehow stimulate animals to be more 
active and cause changes in their activity patterns. But how could the action of yawning achieve these outcomes?

\section{BRAIN COOLING}

Recently, it was proposed that yawns function as a way to cool the brain [4]. According to this brain cooling hypothesis, when the brain is cooled off by yawning, that's what then causes changes in activity levels. There are three things that affect the temperature of the brain: (1) how fast blood is traveling to the brain, (2) the temperature of blood flowing to the brain, and (3) how much heat the brain is producing. For an easy way to think about this, consider what makes your body warm on a hot summer day: (1) how much wind is blowing (or how fast a fan is spinning), (2) how warm or cool the breeze is (regular fan or air conditioner), and (3) how much heat you are producing (exercising or sitting still). According to this brain cooling hypothesis, the physical act of yawning alters the first two conditions: the rate and temperature of blood flowing to the brain. The powerful opening of the jaw produces pressure that forces blood to rush through the blood vessels traveling away from the head (like squeezing water from a sponge), which increases the speed at which fresh blood then flows into the brain. In addition, the deep inhalation of cool air during a yawn reduces the temperature of the blood flowing to the brain. So together, the yawn forces warmer blood away from the hot brain while at the same time bringing in cooler blood from around the lungs (Figure 1). This is similar to what happens in a car radiator, which contains fluid that circulates through the engine to keep the engine from overheating. The radiator is located in the front of the car, so that the passing outside air cools it as you drive. This

\section{FIGURE 1}

Yawning causes the blood flow and the temperature of the brain to change.

A. Yawns are triggered when the brain

temperature rises. B. and

C. The powerful opening of the jaw and the deep inhalation of air produces pressure that forces warm blood to drain away from the skull, indicated by red arrows, while increasing the supply of cooler blood to the brain, indicated by blue arrows. D. Together, this action functions to decrease the brain temperature.

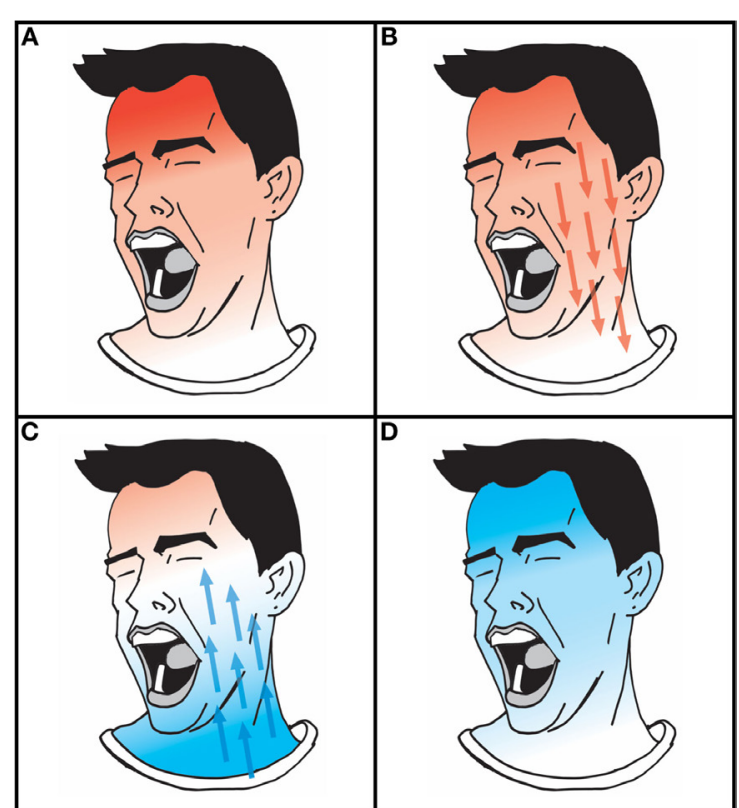

FIGURE 1 
airflow cools the fluid inside the radiator, which then circulates through the engine to decrease the hot engine temperature. The fluid then transfers the heat generated by the hot engine back out to the radiator to be cooled again.

\section{HYPOTHESIS TESTING}

All hypotheses make predictions, which can then be tested by experiments. If these predictions are shown to be true, the hypothesis is supported. For example, if gravity is true, then it is predicted that water will flow downhill, and that when you slip, you fall down rather than up. The brain cooling hypothesis has two basic predictions. First, if yawning serves to cool the brain, then it is predicted that yawns will be triggered by increases in brain temperature and after a yawn, brain temperature will be lower. This prediction has been tested in the laboratory by monitoring changes in the brain temperature of rats [5]. By recording rats' brain temperatures before and after yawns and comparing those temperatures, researchers were able to show that (1) brain temperature increased rapidly before yawns and then (2) decreased shortly after yawns (Figure 2). These results supported the brain cooling hypothesis. In other words, similar to the way that the thermostat on an air conditioner activates when the room becomes too hot, yawns are triggered when brain temperature rises, and this results in a cooling effect that brings the brain back to a normal temperature. Importantly, this doesn't happen only in rats. Similar changes in temperature (as measured by an oral thermometer) have been shown in humans before and after periods of excessive yawning [6]. Therefore, yawns

FIGURE 2

Yawns happen when brain temperature increases, and after yawning, brain temperature decreases.

Time 0 is at the moment of the yawn, with 3 min leading up to (negative values) and following this response (positive values). Yawns are triggered as brain temperature increases from a baseline level shown in blue to a hot state shown in red. After a yawn, brain temperature then drops back down, showing the cooling effect of this response (representation of a study performed by Shoup-Knox et al. [5]).

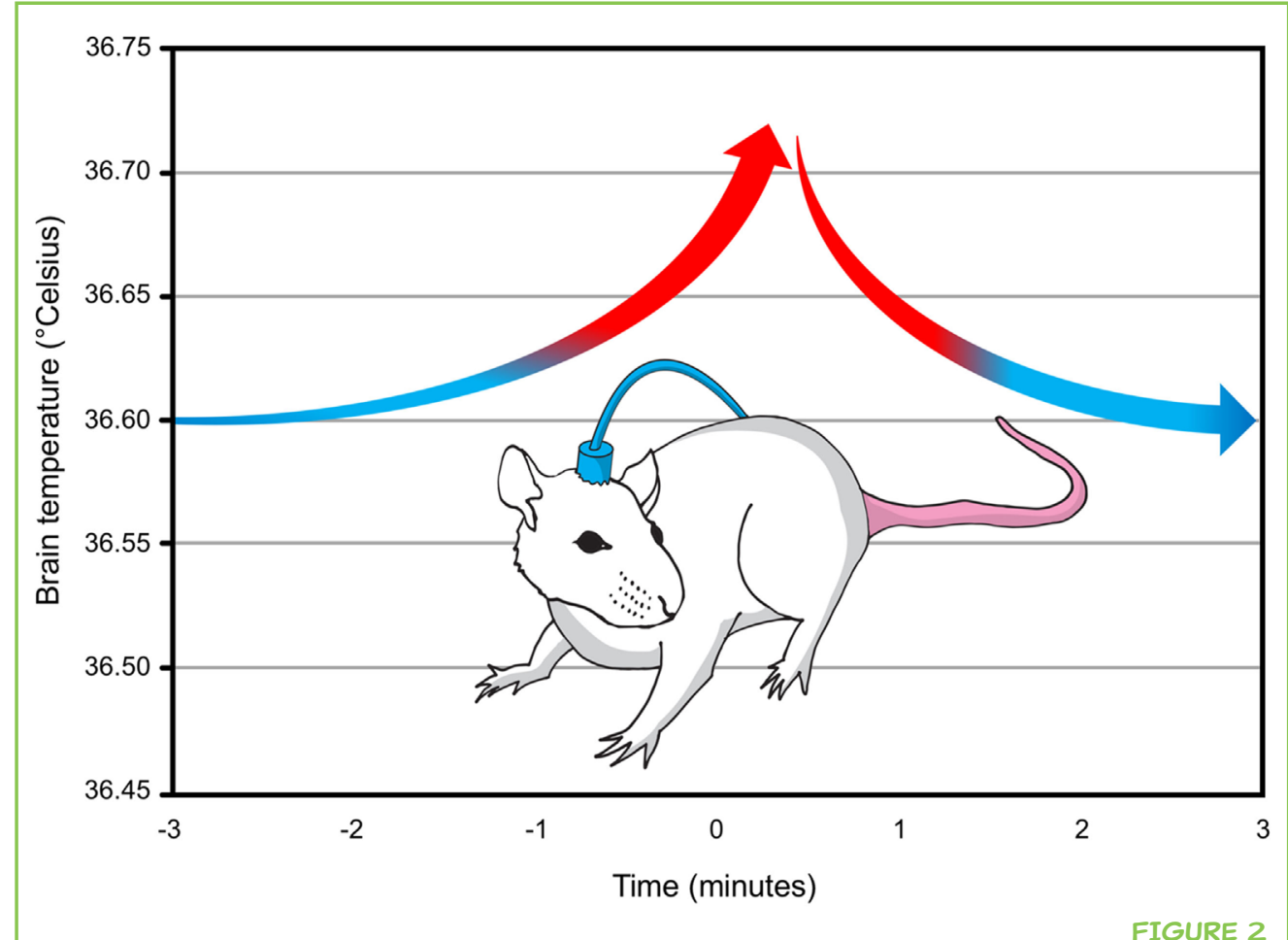


appear to be most strongly and consistently associated with changes in brain and skull temperature, not with the amount of oxygen in the air or how sleepy a person is.

The second basic prediction of the brain cooling hypothesis is that yawning should be affected by changes in the temperature of the surrounding air, which is also known as ambient temperature. In particular, yawning should increase when the ambient temperature increases. When you are outside on a hot summer day, as the ambient temperature increases, so does the temperature of your body, which in turn triggers your body's cooling mechanisms, such as sweating. According to the second prediction of the brain cooling hypothesis, as the ambient temperature increases, yawning should increase, too. But the story is actually more complicated than this. Does jumping into a hot tub to cool off on a hot day sound look a good idea? If you said "no," then you can understand why yawning when it is too hot might also seem like a bad idea. Yawning could actually heat up your brain if the ambient air temperature is warmer than your blood. So, when it is very hot outside, yawns should happen less often, as other cooling mechanisms, such as sweating, kick in. Also, yawns (and other body-cooling mechanisms) are expected to be much less common in colder temperatures. So, as it happens, there is a fairly narrow temperature region where yawning is effective at cooling the brain (Figure 3 ). These predicted patterns of yawning in hot and cold air temperatures have been observed in humans while outdoors in climates such as the desert of Arizona

\section{FIGURE 3}

Changes in ambient temperature affect the frequency of yawning in mammals and birds.

The blue part of the line in the white panel indicates the ambient temperatures at which brain and body temperatures are easily maintained. This is also referred to as the "thermal neutral zone." Once ambient temperatures increase a little bit, shown by the red region of the line, so does the need to cool the brain, which results in an increased yawning rate. However, yawns occur less frequently when the air is very hot or very cold, since taking a deep inhalation of exceedingly warm air would no longer provide a cooling function and cooling mechanisms are not needed in cold environments. and the bitter winters of Austria, as well as in birds and rats in laboratory environments where air temperature can be controlled [7].

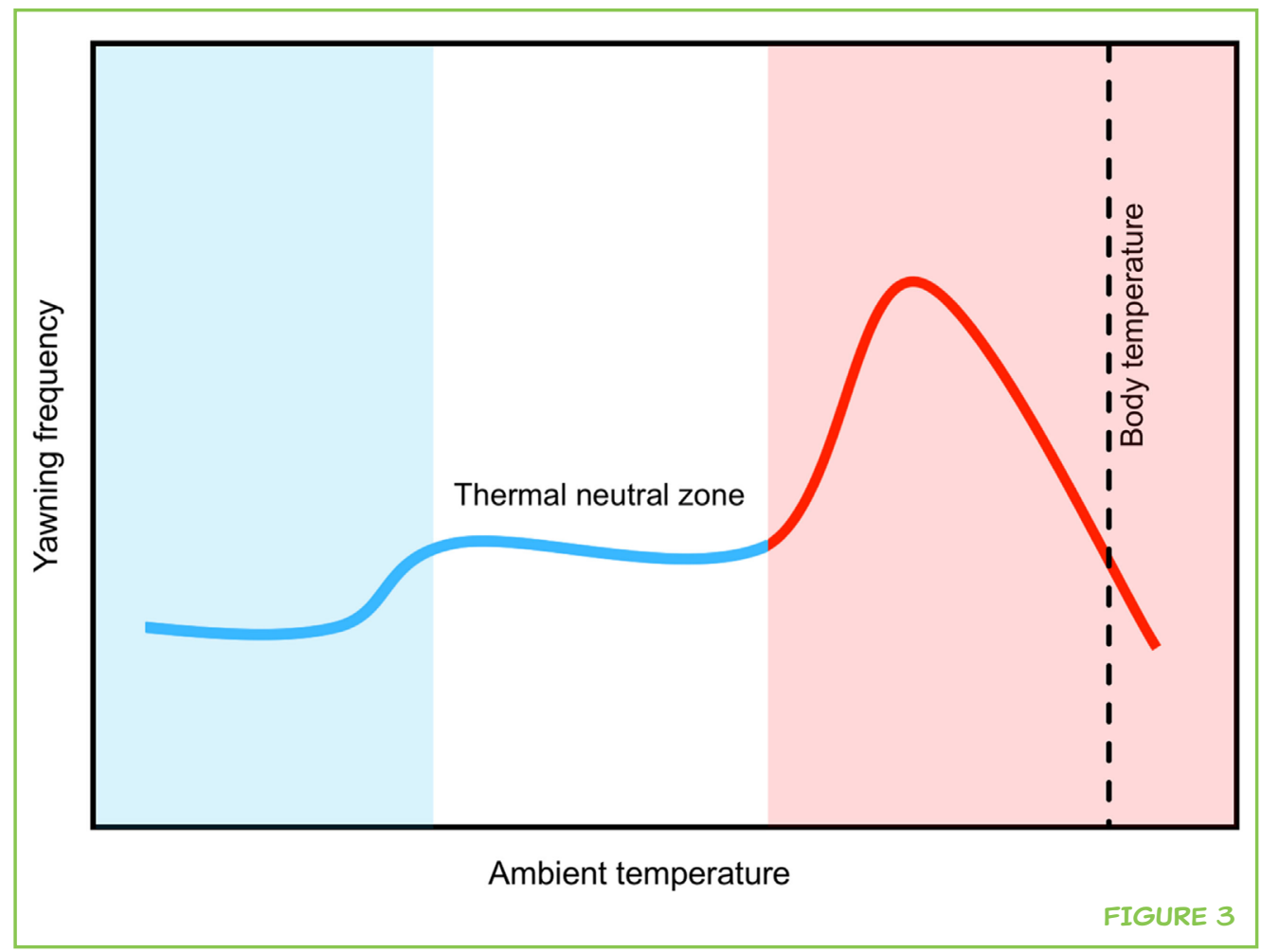




\section{YAWNING EXPLAINED}

The brain cooling hypothesis can also explain why yawning happens in a variety of other related situations. For example, some medical reports have shown a strong connection between brain temperature and yawning frequency. A number of medical conditions and prescription drugs that increase brain temperature have been shown to increase the occurrence of yawning, while medical conditions and drugs that produce a decrease in brain temperature reduce the occurrence of yawns [8]. The brain cooling hypothesis also helps us to understand the connection between yawning and sleep, since major changes in brain and body temperature occur in the morning and evening hours, when yawning happens most often. For example, brain and body temperatures rise rapidly when we wake up in the morning and are highest in the evening before we fall asleep. The fact that yawning occurs as a result of stress is also consistent with the brain cooling hypothesis, since stress and anxiety are associated with increases in body temperature.

The brain cooling hypothesis can also explain differences in the way animals yawn. There is a general rule in nature; bigger things take longer to heat up and cool down, compared with smaller things. This is why a large pot of water takes much longer to boil in comparison with a smaller one. This is also why large bodies of water, like lakes and even swimming pools, do not become covered with ice until well after the air temperature drops below freezing, but in comparison, it only takes a few hours to make ice cubes in the freezer. We can think about the brain cooling effects of yawning in a similar way. Larger brains should also take longer to cool than smaller brains. To test this prediction, researchers recently examined whether differences in how long a yawn lasts were associated with brain size. They examined a large group of different mammals [9]. As predicted, species with larger brains, but not necessarily larger bodies, experienced longer yawns compared with species with smaller brains.

Last, the brain cooling hypothesis helps to explain why yawns are contagious (something you have likely experienced by now, while reading this article). If yawning is a brain cooling mechanism that helps to change the activity level in the body, the contagious spreading of yawning between individuals may help to coordinate the behavior of all the members in the group. In other words, if yawning helps prepare a bird to shift from resting to flying, then it makes sense for the rest of the flock to coordinate their behavior and get ready to fly, too.

\section{A NEW PERSPECTIVE FOR AN OLD BEHAVIOR}

In addition to improving our basic understanding of this common behavior that many people don't often think about, this new perspective on yawning as a brain cooling mechanism might be useful in a number of ways. For example, research on yawning could improve the treatment and diagnosis of medical 
conditions with frequent yawning in which individuals are not able to keep their brains and bodies at a normal temperature, such as patients with epilepsy or multiple sclerosis. In addition, a better understanding of yawning could improve how we identify and work to fight excessive sleepiness, or even to improve the brain's performance during long periods of attention and focus. Understanding the relationship between stress and yawning can also help us to understand the emotional state of non-human animals that otherwise cannot communicate with us. Now, the next time someone mentions how yawning is rude or disrespectful, encourage them to read this article so they can learn more about the function of this behavior and why yawns are so important, and so cool.

\section{ACKNOWLEDGMENTS}

We thank Bassem Eldakar for providing the illustrations.

\section{ORIGINAL SOURCE ARTICLE}

Gallup, A. C., and Eldakar, O. T. 2013. The thermoregulatory theory of yawning: what we know from over 5 years of research. Front. Neurosci. 6:188. doi:10.3389/ fnins.2012.00188

\section{REFERENCES}

1. Provine, R. R., Tate, B. C., and Geldmacher, L. L. 1987. Yawning: no effect of 3-5\% $\mathrm{CO}_{2}, 100 \% \mathrm{O}_{2}$, and exercise. Behav. Neural. Biol. 48:382-93. doi:10.1016/S01631047(87)90944-7

2. Provine, R. R. 2005. Yawning: the yawn is primal, unstoppable and contagious, revealing the evolutionary and neural basis of empathy and unconscious behavior. Am. Sci. 93:532-9. doi:10.1511/2005.56.980

3. Baenninger, R. 1997. On yawning and its functions. Psychon. Bull. Rev. 4:198-207. doi:10.3758/BF03209394

4. Gallup, A. C., and Gallup, G. G. Jr. 2007. Yawning as a brain cooling mechanism: nasal breathing and forehead cooling diminish the incidence of contagious yawning. Evol. Psychol. 5:92-101. doi:10.1177/147470490700500109

5. Shoup-Knox, M. L., Gallup, A. C., Gallup, G. G., and McNay, E. C. 2010. Yawning and stretching predict brain temperature changes in rats: support for the thermoregulatory hypothesis. Front. Evol. Neurosci. 2:108. doi:10.3389/ fnevo.2010.00108

6. Gallup, G. G., and Gallup, A. C. 2010. Excessive yawning and thermoregulation: two case histories of chronic, debilitating bouts of yawning. Sleep Breath. 14:157-9. doi:10.1007/s11325-009-0287-x

7. Gallup, A. C. 2016. Ambient temperature modulates yawning. Temperature 3:23. doi:10.1080/23328940.2015.1066925 
8. Gallup, A. C., and Gallup, G. G. 2008. Yawning and thermoregulation. Physiol. Behav. 95:10-6. doi:10.1016/j.physbeh.2008.05.003

9. Gallup, A. C., Church, A. M., and Pelegrino, A. J. 2016. Yawn duration predicts brain weight and cortical neuron number in mammals. Biol. Lett. 12:20160545. doi:10.1098/rsbl.2016.0545

SUBMITTED: 06 June 2017; ACCEPTED: 01 September 2017; PUBLISHED ONLINE: 20 September 2017.

EDITED BY: Sabine Kastner, Princeton University, United States

CITATION: Gallup AC and Eldakar OT (2017) Yawns Are Cool. Front. Young Minds 5:52. doi:10.3389/frym.2017.00052

CONFLICT OF INTEREST STATEMENT: The authors declare that the research was conducted in the absence of any commercial or financial relationships that could be construed as a potential conflict of interest.

COPYRIGHT @ 2017 Gallup and Eldakar. This is an open-access article distributed under the terms of the Creative Commons Attribution License (CC BY). The use, distribution or reproduction in other forums is permitted, provided the original author(s) or licensor are credited and that the original publication in this journal is cited, in accordance with accepted academic practice. No use, distribution or reproduction is permitted which does not comply with these terms.

\section{REVIEWED BY}

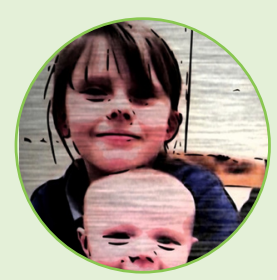

\section{AMY, 8 YEARS OLD}

I love gymnastics and playing on my tablet. My mummy is a psychologist and my daddy works for a company that makes machines for brain surgeons. I have a friend who is a brain surgeon too. I have a little brother who is four and a half months old. I love my whole family and I like to read.
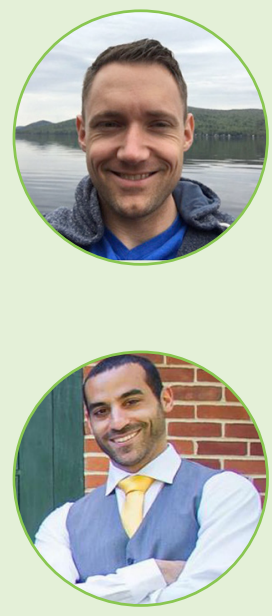

\section{AUTHORS}

\section{ANDREW C. GALLUP}

Andrew C. Gallup is a professor of evolutionary cognitive neuroscience at SUNY Polytechnic Institute, in Utica, NY, USA. He holds general interests in adaptive behavior and physiology and has become a world authority on yawning research. He is a strong advocate for evolution education and has served as an editor for a number of scientific journals. *a.c.gallup@gmail.com

\section{OMAR TONSI ELDAKAR}

Omar Tonsi Eldakar is a professor of evolutionary biology at Nova Southeastern University, in Fort Lauderdale, FL, USA. He investigates the evolution of cooperation and conflict, and other ways in which organisms interact with each other. He studies these interactions in a broad range of organisms from bacteria to insects to humans. While he specializes in social behavior, he also maintains general interests in the role of natural selection on shaping behavior. 